\title{
Lymphocytic choriomeningitis virus meningitis after needlestick injury: a case report
}

\author{
Sarah Dräger ${ }^{1 *}$, Anna-Friederike Marx ${ }^{2}$, Fiona Pigny ${ }^{3}$, Pascal Cherpillod ${ }^{3}$, Philip Eisermann ${ }^{4}$, Parham Sendi ${ }^{1,5}$ and \\ Andreas F. Widmer'
}

\begin{abstract}
Background: Needlestick accidents while handling of infectious material in research laboratories can lead to lifethreatening infections in laboratory personnel. In laboratories working with the lymphocytic choriomeningitis virus (LCMV), the virus can be transmitted to humans through needlestick injury and lead to serious acute illness up to meningitis.

Case presentation: We report of a case of LCMV meningitis in a laboratory worker who sustained a penetrating needlestick injury with a LCMV-contaminated hollow needle whilst disposing of a used syringe into the sharps waste bin. Four days after needlestick injury the laboratory worker developed a systemic disease: 11 days after exposure, she was diagnosed with meningitis with clinical signs and symptoms of meningismus, photophobia, nausea and vomiting, requiring hospitalisation. The PCR was positive for LCMV from the blood sample. 18 days after exposure, seroconversion confirmed the diagnosis of LCMV-induced meningitis with an increase in specific LCMVIgM antibodies to 1:10'240 (day 42: 1:20'480). Ten weeks after exposure, a follow-up titre for lgM returned negative, whereas lgG titre increased to 1:20'480.

Conclusions: This is the first case report of a PCR-documented LCMV meningitis, coupled with seroconversion, following needlestick injury. It highlights the importance of infection prevention practices that comprise particularly well established safety precaution protocols in research laboratories handling this pathogenic virus, because exposure to even a small amount of LCMV can lead to a severe, life-threatening infection.
\end{abstract}

Keywords: Lymphocytic choriomeningitis virus, Meningitis, Needlestick injury, Accidental infection, RT-PCR

\section{Background}

LCMV infection is usually asymptomatic or mild and self-limiting, but rarely can manifest itself as severe disease such as meningitis and encephalitis [1]. In organ transplant recipients and immunocompromised patients such an infection can be life-threatening [2, $3]$. Congenital infections can result in life-long mental retardation and vision deficits [4]. House mice (Mus musculus) are the common host of LCMV, a member of the family of Arenaviridae. Modes of transmission to humans are bites of infected mice, inhalation of

\footnotetext{
* Correspondence: sarah.draeger@usb.ch

Data presented on ECCMID on April 21, 2018 as poster presentation.

'Infectious Diseases and Hospital Epidemiology, University Hospital Basel,

Petersgraben 4, 4031 Basel, Switzerland

Full list of author information is available at the end of the article
}

aerosolized droplets of contaminated body fluids or inoculation of contaminated materials into broken skin, the eyes or the mouth [5].

We report of well-documented LCMV-meningitis of a laboratory worker after needlestick injury confirmed by serological tests and direct detection of viral RNA in blood by PCR. A previous case report of lab-acquired LCMV infection was based on indirect evidence by serological tests, not direct detection of viral RNA by PCR [6]. There is no evidence-based standard drug available for post-exposure prophylaxis: Therefore, prevention of stab wounds with contaminated sharp objects, bite of infected mice and inhalation of contagious droplets, is indispensable to

(c) The Author(s). 2019 Open Access This article is distributed under the terms of the Creative Commons Attribution 4.0 International License (http://creativecommons.org/licenses/by/4.0/), which permits unrestricted use, distribution, and reproduction in any medium, provided you give appropriate credit to the original author(s) and the source, provide a link to the Creative Commons license, and indicate if changes were made. The Creative Commons Public Domain Dedication waiver (http://creativecommons.org/publicdomain/zero/1.0/) applies to the data made available in this article, unless otherwise stated. 
protect laboratory worker from occupational severe infection, leading even to epidemics [7].

This highlights the importance of infect prevention strategies that comprise particularly well established safety precaution protocols in research laboratories handling this pathogenic virus, because exposure to LCMV can lead to a life-threatening infection.

\section{Case presentation}

In May 2017, a young scientist accidently sustained a penetrating needlestick injury to the left index finger from a LCMV-contaminated needle, whilst disposing of a used syringe in a correct manner into the inaccurate overfilled sharps waste bin. The needle stuck on a syringe that was used to infect mice with Lymphocytic choriomeningitis virus (LCMV) variant clone-13. For its distinct use, the syringe was filled up with $200 \mu \mathrm{L}$ fluid solution containing a LCMV-concentration of $9.15 \times 10^{6} \quad$ Plaque-forming units $(\mathrm{PFU}) / \mathrm{ml}$ and was littered after its use, presumably completely emptied. The estimated inoculated volume was approximately $1 \mu \mathrm{L}$ (corresponding to $9.15 \times 10^{3} \quad$ PFU). Following strictly the laboratory safety protocol, first aid measures were taken immediately after the injury by washing and disinfecting the wound. A check-up at the university emergency room (ER) the same day, with clinical examination and blood tests remained unremarkable. As there is no known well-established medicamentous post-exposure prophylaxis, the patient was discharged and was advised to return to the ER if any signs of illness occur.

Four days after needlestick injury, she developed systemic illness, comprising acute severe lower back pain and fatigue (Fig. 1).

Seven days after exposure, her clinical situation deteriorated by developing flu-like illness with cough, pharyngitis, neck pain, fever up to $38.3^{\circ} \mathrm{C}$, chills and pain in the limbs. She presented to the ER where physical examination revealed no signs of meningitis or focal neurological deficits. Blood tests showed acute leukopenia $\left(2.1 \times 10^{9} / \mathrm{l}\right)$ and lymphopenia $\left(0.57 \times 10^{9} / 1\right) \quad$ (Additional file 1: Figure S1), but $\mathrm{C}$-reactive protein and liver function tests were within the normal range (data not shown). She was discharged with symptomatic, pain-relieving therapy.

Nine days after needlestick injury, symptoms of systemic illness, especially headaches and back pain,

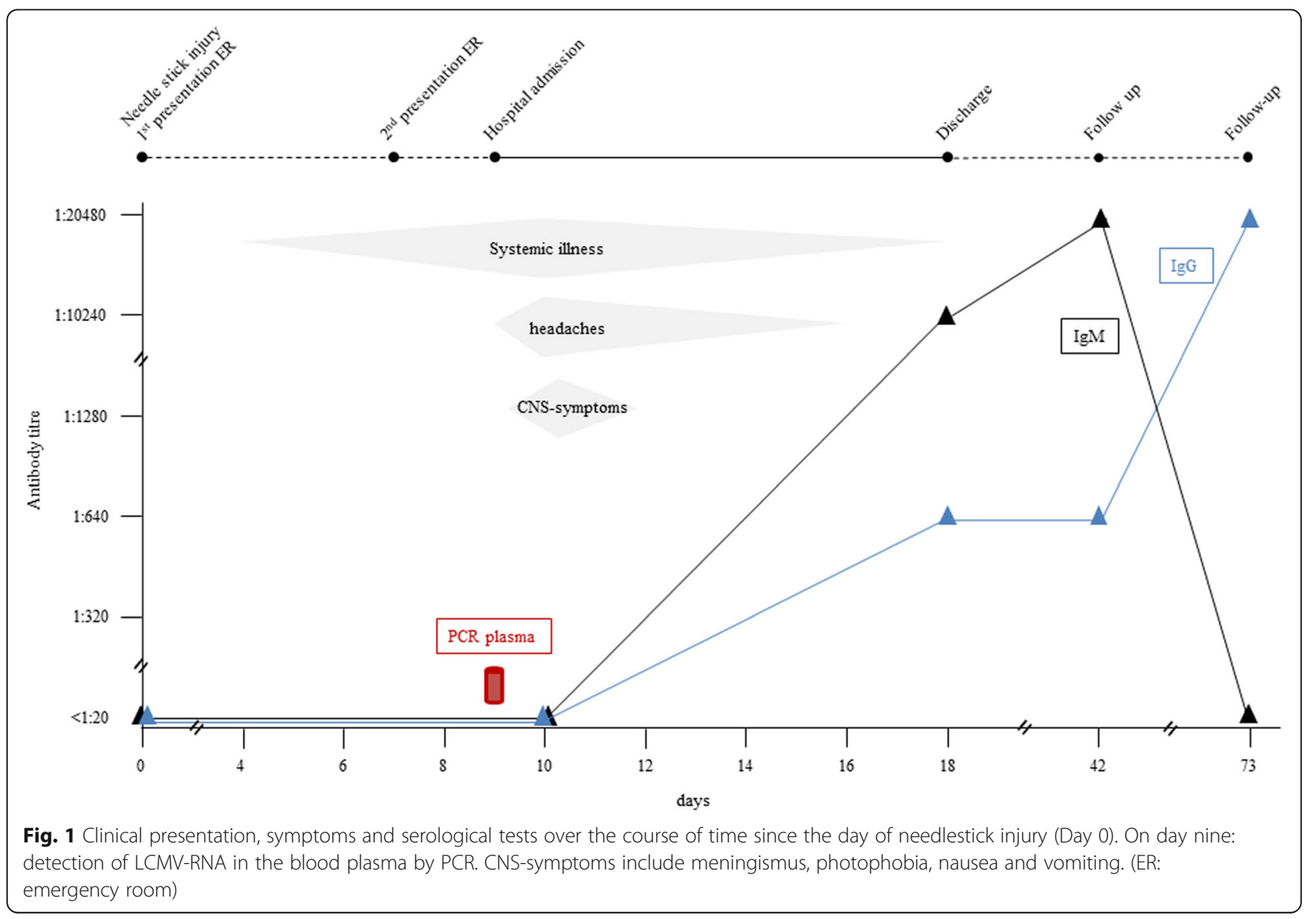


relapsed and worsened over time. She was admitted to the hospital where supportive care measures - rehydration and intensified pain relief - were established. Cerebrospinal fluid (CSF) showed cell count in the normal range as well as protein, glucose and lactate level. Serological tests were reactive for tick-borne-encephalitis (IgG and IgM positive) consistent with her known positive vaccine status. A multiplex polymerase chain reaction (PCR) performed in the CSF, including six bacterial species, seven viruses and one yeast, remained negative. MRI of the lumbar spine and the brain showed no evidence for abscess or meningeal enhancement. Thrombocytes dropped from $156 \times 10^{9} / 1$ to $92 \times 10^{9} / 1$ and lymphocytes from $0.57 \times 10^{9} / 1$ to $0.36 \times 10^{9} / 1$, consistent with onset of acute viral infection (Additional file 1: Figure S1).

11 days after exposure, she was diagnosed with meningitis, with clinical signs and symptoms of meningismus, photophobia, nausea and vomiting, suggesting acute LCMV-meningitis.

Blood plasma samples that were drawn nine days after injury were simultaneously sent to the Laboratory of Virology at the University Hospital of Geneva and to the Bernhard Nocht Institute for Tropical Medicine in Hamburg for LCMV-PCR. The Geneva laboratory performed an LCMV-specific real-time reverse transcriptase (RT)-PCR assay [8] and reported a positive PCR signal for LCMV from the blood sample. Although CT-Value was high, indicating a low viral load (CT Mean 40.868), the signal was clearly positive. The other reference laboratory in Hamburg obtained a negative result using a conventional RT-PCR assay [9]. LCMV-PCR performed in two urine samples (day 14 and 15 after exposure) and in the CSF (day nine after exposure) remained negative, reported by the Geneva laboratory. Serological testing was performed in Hamburg by immunofluorescence assays using LCMV-infected cells as antigen. At day of the needlestick injury and ten days after exposure, the patient was tested negative for LCMV-specific IgM as well as IgG (Fig. 1).

12 days after exposure the patient improved, and laboratory findings returned to normal ranges.

18 days after exposure, seroconversion with an increase in specific LCMV-IgM antibodies to $1: 10^{\prime} 240$ (day 42: 1:20'480; negative reference $<1: 20$ ) was confirmed (s. Figure 1). Already to that point of time, an increase in specific LCMV-IgG-antibodies to 1:640 could be noted (day 42: 1:640; negative reference <1:20) (s. Figure 1). Ten weeks after exposure, a follow-up titre for IgM returned negative, whereas IgG titre increased up to $1: 20^{\prime} 480$ (s. Figure 1). Diagnosis of acute LCMV meningitis after needlestick injury was based on epidemiological links and exposure, clinical signs and symptoms, seroconversion in plasma and detection of virus RNA in blood plasma by PCR. A diagnostic work-up at the clinic of neurology did not find any evidence for an alternative diagnosis.

\section{Discussion and conclusion}

House mice are the common host of LCMV, a member of the family of Arenaviridae. Modes of transmission to humans are bites of infected rodents, inhalation of aerosolized droplets of contaminated body fluids or inoculation of contaminated materials into broken skin, the eyes or the mouth [5]. LCMV infection is usually asymptomatic or mild and self-limiting, but rarely can manifest itself as meningitis and encephalitis [1]. In organ transplant recipients and immunocompromised patients, such infections can be life-threatening $[2,3]$. Congenital infections can result in life-long mental retardation and vision deficits [4]. The incubation period usually is eight to 13 days followed typically by a biphasic febrile illness [10]. The initial phase begins with fever, malaise, muscle aches, headache and nausea and is lasting for about one week [10]. After a few days of recovery signs of meningoencephalitis occur [10]. Our patient developed this typical biphasic illness, though it already occurred four days after exposure. The cause of the shorter incubation period is most likely the high inoculum with which the patient has become infected and the mode of transmission via direct inoculation in the skin.

It is of note that even in patients presenting with signs and symptoms of meningitis, CSF cell count still can be in the normal range as well as protein, glucose and lactate level.

We assume that the conventional RT-PCR that was used in Hamburg might be less sensitive than the LCMV-specific real-time RT-PCR performed in Geneva leading to the differing results. In vitro, detection limit of RT-PCR is $20 \mathrm{PFU} / \mathrm{mL}$, whereas RNA-detection of real-time RT-PCR can succeed with viral amounts of $\leq 10 \mathrm{PFU} / \mathrm{mL}[8,9]$. PCR-signal obtained with real-time RT-PCR was weak but clearly positive (CT Mean 40.868), indicating a very low viral load.

This is the first published case report of well-documented LCMV-meningitis after needlestick injury confirmed by serological tests and direct detection of viral RNA in blood by PCR. A previous case report of iatrogenic LCMV infection was based on indirect evidence by serological tests, not direct virus detection by PCR, although the inoculum was presumably significantly higher than in our case [6]. There is no evidence-based standard drug available for post-exposure prophylaxis. The role of ribavirin in LCMV infection remains unclear. In mice, an effectiveness of ribavirin has been demonstrated, but this effect remains unclear in humans [2]. Prevention of stab wounds with contaminated sharp 
objects, bite of infected mice and inhalation of contagious droplets, is crucial to protect laboratory worker from iatrogenic infection, leading even to epidemics [7]. LCMV-outbreaks in healthcare workers [11] and laboratory personnel $[12,13]$ are well described. The source of illness for these outbreaks are rodents that have been infected with LCMV for research purposes. LCMV then was transmitted to humans either via direct intimate contact with LCMV-infected rodents $[12,13]$ or by indirect contact via aerosol exposure demonstrating the risk for transmission [11, 13]. Therefore, laboratory personnel must be instructed of the possible transmission routes and clinical presentation of LCMV with repetitive instructions on safe handling of LCMV. When working with LCMV, high quality gloves, goggles and protective gowns must be worn, as well as appropriate ventilation systems should be in place where animals are handled. Surfaces should be routinely disinfected using a certified compound active against LCMV. In addition, a standard operating procedure should be available for the management of unintentional exposure to the virus. Pregnant women and immunosuppressed persons must be taught that exposure to even a small amount of this pathogenic virus can lead to a severe, life-threatening infection.

In conclusion, this well-documented case of LCMV-meningitis after needlestick injury highlights the importance of infection prevention practices in research laboratories and the need of safe handling of this virus, whose pathogenicity often is underestimated.

\section{Additional file}

Additional file 1: Figure S1: Thrombocytes, neutrophils and lymphocytes over the course of time after day of needlestick injury. (TIF $27480 \mathrm{~kb}$ )

\section{Abbreviations}

CSF: Cerebrospinal fluid; ER: Emergency room; LCMV: Lymphocytic choriomeningitis virus; PCR: Polymerase chain reaction; PFU: Plaque-forming unit; RT: Reverse transcriptase

\section{Acknowledgements}

Not applicable.

\section{Funding}

Not applicable.

\section{Availability of data and materials}

The datasets used and analysed during the current study are available from the corresponding author on reasonable request.

\section{Authors' contributions}

FP, PC and PE analyzed and interpreted the PCR results and the serological test results. A-FM provided the clinical data. AFW, PS and SD interpreted the results and were major contributor in writing the manuscript and in designing the figures. All authors read and approved the final manuscript.

\section{Ethics approval and consent to participate}

The young scientist agreed that her case should be published and contributed in the writing of the manuscript.

\section{Consent for publication}

The young scientist consented for publication.

\section{Competing interests}

The authors declare that they have no competing interests.

\section{Publisher's Note}

Springer Nature remains neutral with regard to jurisdictional claims in published maps and institutional affiliations.

\section{Author details}

${ }^{1}$ Infectious Diseases and Hospital Epidemiology, University Hospital Basel, Petersgraben 4, 4031 Basel, Switzerland. ${ }^{2}$ Department of Biomedicine - Haus Petersplatz, Division of Experimental Virology, University of Basel, 4009 Basel, Switzerland. ${ }^{3}$ Laboratory of Virology, Department of Genetic and Laboratory Medicine, University Hospitals of Geneva, Rue Gabrielle-Perret-Gentil 4, 1211, 14 Geneva, Switzerland. ${ }^{4}$ WHO Collaborating Centre for Arbovirus and Haemorrhagic Fever Reference and Research, Bernhard Nocht Institute for Tropical Medicine, Bernhard-Nocht-Strasse 74, 20359 Hamburg, Germany. Institute for Infectious Diseases, University of Bern, Freiburgstrasse 18, 3010 Bern, Switzerland.

Received: 14 November 2018 Accepted: 16 April 2019

Published online: 20 May 2019

\section{References}

1. Barton LL. Lymphocytic choriomeningitis virus: a neglected central nervous system pathogen. Clin Infect Dis. 1996;22(1):197.

2. Fischer SA, Graham MB, Kuehnert MJ, Kotton CN, Srinivasan A, Marty FM, et al. Transmission of lymphocytic choriomeningitis virus by organ transplantation. N Engl J Med. 2006:354:2235-49.

3. Palacios G, Druce J, Du L, Tran T, Birch C, Briese T, et al. A new arenavirus in a cluster of fataltransplant-associated diseases. N Engl J Med. 2008:358:991-8.

4. Barton LL, Budd SC, Morfitt WS, Peters CJ, Ksiazek TG, Schindler RF, et al. Congenital lymphocytic choriomeningitis virus infection in twins. Pediatr Infect Dis J. 1993;12(11):942-6.

5. Emonet S, Retornaz K, Gonzalez JP, de Lamballerie X, Charrel RN. Mouse-tohuman transmission of variant lymphocytic choriomeningitis virus. Emerg Infect Dis. 2007;13(3):472-5.

6. Aebischer O, Meylan P, Kunz S, Lazor-Blanchet C. Lymphocytic choriomeningitis virus infection induced by percutaneous exposure. Occup Med (Lond). 2016:66(2):171-3.

7. Knust B, Ströher U, Edison L, Albariño C, Lovejoy J, Armeanu E, et al. Lymphocytic choriomeningitis virus in employees and mice at multipremises feeder-rodent operation, United States, 2012. Emerg Infect Dis. 2014;20:240-7.

8. Cordey S, Sahli R, Moraz ML, Estrade C, Morandi L, Cherpillod P, et al. Analytical validation of a lymphocytic choriomeningitis virus real-time RTPCR assay. J Virol Methods. 2011;177(1):118-22.

9. Vieth S, Drosten C, Lenz O, Vincent M, Omilabu S, Hass M, et al. RT-PCR assay for detection of Lassa virus and related Old World arenaviruses targeting the L gene. Trans R Soc Trop Med Hyg. 2007;101(12):1253-64.

10. Lymphocytic Choriomeningitis (LCM), signs and symptoms (2014, may 6). Accessed March 21, 2019. https://www.cdc.gov/vhf/lcm/symptoms/index. html

11. Hinman AR, Fraser DW, Douglas RG, Bowen GS, Kraus AL, Winkler WG, et al. Outbreak of lymphocytic choriomeningitis virus infections in medical center personnel. Am J Epidemiol. 1975;101(2):103-10.

12. Baum SG, Lewis AM Jr, Rowe WP, Huebner RJ. Epidemic nonmeningitic lymphocytic-choriomeningitis-virus infection: an outbreak in a population of laboratory personnel. N Engl J Med. 1966;274:934-6.

13. Dykewicz CA, Dato VM, Fisher-Hoch SP, Howarth MV, Perez-Oronoz Gl, Ostroff SM, et al. Lymphocytic choriomeningitis outbreak associated with nude mice in a research institute. JAMA. 1992;267(10):1349-53. 